\title{
Comparative Empirical Analysis of Female University Enrolment in STEM Courses in the Geopolitical Zones in Nigeria
}

\author{
Bukola A. Onyekwelu \\ Department of Mathematics and Computer Science, Elizade University, P. M. B. 002, Ilara-Mokin, Nigeria. \\ Email: bukola-onyekwelu@elizadeuniversity.edu.ng
}

Received: 17 October 2018; Accepted: 15 November 2018; Published: 08 January 2019

\begin{abstract}
Though University enrolment in Nigeria is on the increase, more males than females are still being enrolled today, which varies according to discipline as well as from one geopolitical zone of the country to another. This is more pronounced in Science, Technology, Engineering and Mathematics fields, as female enrolment seems to be higher in the commercial and arts courses than the sciences and engineering. Secondary data were obtained from the Nigerian Bureau of Statistics, based on the Joint Admission and Matriculation Board registrations for a period of 5 years, spanning 2011 to 2015. The data were classified based on the six geopolitical zones in Nigeria, and multivariate data analysis, supported by Multivariate Analysis of Variance was carried out on the data. The results obtained revealed that there is still a wide variance in male and female enrolment in these fields, with male enrolment being significantly higher than that of female candidates. It also revealed that female enrolment varies depending on the geopolitical zone, with female enrolment in Science, Technology, Engineering and Mathematics being generally higher in geographical zones in southern Nigeria compared with those in northern Nigeria. The results obtained were further compared with data obtained from previous researches and the comparison was discussed. In addition, this study offers recommendations on how to encourage more female participation in Science, Technology, Engineering, and Mathematics.
\end{abstract}

Index Terms-University, enrolment, STEM, geopolitical zones, variance, parity

\section{INTRODUCTION}

Reference [1] described Comparative research as a general concept that comprises both quantitative and qualitative comparison of social entities. In the case of this study, the social entities here are male and female students, their enrolment into science courses, in the six geopolitical zones of Nigeria. It has been observed over the years that enrolment into the study of courses in the Science, Technology, Engineering, and Mathematics
(STEM) fields tend to be less than those of courses in the fields of Arts and Humanities. Slyvie, et al as cited in [2] explained that this tendency is a common phenomenon in many countries, stating Germany as an example, where $50 \%$ decrease was recorded within the last 20 years. This is even more pronounced in developing countries, especially in Nigeria. On the overall, it has been found that the statistical difference between male and female enrolment in Nigerian universities have been consistent, with female enrolment being consistently lower than that of the male [3]. This problem did not begin with university enrolment, but far back to primary education. British Council Report [4] reported that, at the primary school level, fewer girls than boys enrolled in school, and the majority of out-of-school children are girls. The difference is even more pronounced in the female participation in STEM courses when compared with that of the male counterparts [2].

Reference [3] carried out some comparative analysis of some University enrolments in Nigeria with the aim of highlighting participation in University education by gender and locating the gender participation disparity barriers in University education in the country. He analyzed data on enrolment by gender, within the period of 2003 to 2007. From his findings, he concluded that very little progress was made in closing the gender gap, within the period of study. He went on to identify some intervention strategies that can help close the existing gap between male and female in access to University education in Nigeria.

Reference [5] compared data obtained from the National Universities Commission (NUC), Digest of Statistics Abuja, and revealed that there was less female enrolment in all courses in the Universities compared to their male counterpart, that there was a wide gap in the science-based disciplines compared to arts and humanities-based disciplines, as well as between the Northern and the Southern zones, with higher female enrolment in the south than in the north. Based on their findings, [5] recommended running programmes to enlighten people, fine-tuning labor laws and accommodating female under the "educationally disadvantaged" admission policy being enjoyed by some citizens of the country. 
Reference [6] carried out a study of the enrolment, graduation and staffing pattern of male and female gender in Science and Technology fields in Nigerian higher institutions over a period of ten years (1997-2006). They used structured questionnaires and interviews to get primary data from some female undergraduates in the field of natural sciences and engineering, in the six geopolitical zones of Nigeria. They also employed secondary data. They went ahead to compare the data with that from some other countries, in order to identify differences and similarities. From their findings, they observed that though there has been increased awareness among girls at secondary school levels, the pattern showed that the female enrolment was lower than that of the male.

It is obvious from the above that it is necessary to undertake studies to examine if the enrolment of female students into STEM courses has increased in recent times as well as to evaluate if there are changes in the dynamics of the enrolment across geopolitical zones of Nigeria. This paper attempts to fill this knowledge gap. The paper focuses on the comparative analysis of the pattern of female enrolment into STEM courses in Nigerian Universities in the six geopolitical zones in Nigeria in recent years. The results of the current study will be compared with those of previous years, to see if there are any change in dynamics of enrolment if there are improvements, and where the improvements occurred.

\section{METHODOLOGY}

\section{A. Data Collection and Analysis}

The data used in this research are secondary data obtained from [7], from the National Bureau of Statistics, Abuja Nigeria. According to the Bureau, the data was primarily obtained from administrative records, surveys, and censuses, and the validity of the data was carefully confirmed to reduce significantly, issues related to errors. The data are the Admission Statistics by Sex, States of Origin and Faculty from the Joint Admission and Matriculation Board (JAMB), for a period of 6 years (i.e. from $2010-2015)$. Since the focus of this research is on female admission into Science, Technology, Engineering and Mathematics (STEM) courses, all the courses in these

Table 1. The Six Geopolitical Zones of Nigeria

\begin{tabular}{|c|c|c|}
\hline $\mathrm{S} / \mathrm{N}$ & $\begin{array}{l}\text { Geopolitical } \\
\text { Zones }\end{array}$ & States \\
\hline 1. & Middlebelt & $\begin{array}{l}\text { Benue, Kogi, Kwara, Nasarawa, } \\
\text { Niger, Plateau, Federal Capital } \\
\text { Territory }\end{array}$ \\
\hline 2. & Northeast: & $\begin{array}{l}\text { Adamawa, Bauchi, Borno, Gombe, } \\
\text { Taraba. Yobe }\end{array}$ \\
\hline 3. & Northwest: & $\begin{array}{l}\text { Jigawa, Kaduna, Kano, Katsina, } \\
\text { Kebbi, Sokoto, Zamfara }\end{array}$ \\
\hline 4. & Southeast: & $\begin{array}{l}\text { Abia, Anambra, Ebonyi, Enugu, } \\
\text { Imo }\end{array}$ \\
\hline 5. & Southsouth: & $\begin{array}{l}\text { Akwa Ibom, Cross River, Bayelsa, } \\
\text { Rivers, Delta, Edo }\end{array}$ \\
\hline 6. & Southwest: & $\begin{array}{l}\text { Ekiti, Lagos, Ogun, Ondo, Osun, } \\
\text { Oyo }\end{array}$ \\
\hline
\end{tabular}

categories were grouped together, to be contrasted with other courses outside the categories. The States were also classified into the six (6) geopolitical zones in Nigeria, as shown in Table 1.

\section{B. Results}

The data was analyzed using the Analysis of Variance (ANOVA) technique. ANOVA is a statistical model that is used in analyzing differences among means in a data collection. According to Reference [12], ANOVA is acceptable in experimental designs with one dependent variable that is a continuous parametric numerical outcome measure, and multiple experimental groups within one or more independent (categorical) variables. The results of the Analysis of Variance revealed significant differences $(p<0.05)$ in the total number of students' enrolment in higher institutions (Universities and Polytechnics) across geographical zones of Nigeria. Enrolments were also found to differ significantly between years of enrolment, the gender of students and specialization.

The total number of students' enrolment was significantly lower in the year $2010(192,238)$ than those of all the other years (between 344,836 and 425,370), which were not significantly different $(p>0.05)$ from each other (Table 2). The breakdown of enrolment was found to differ significantly between the different geopolitical zones, as shown in Table 3.

Table 2. Total Students' Enrolment by Year (between 2010 and 2015)

\begin{tabular}{cc}
\hline Year & Total enrolment \\
\hline 2010 & $192,238^{\mathrm{b}}$ \\
2011 & $344,836^{\mathrm{a}}$ \\
2012 & $425,370^{\mathrm{a}}$ \\
2013 & $412,872^{\mathrm{a}}$ \\
2014 & $354,076^{\mathrm{a}}$ \\
\hline
\end{tabular}

Note: values in the same column with the same superscript are not significantly

Table 3. Results of students' enrolment in the six geopolitical zones in Nigeria between 2010 and 2015

\begin{tabular}{cc}
\hline Geopolitical zones & $\begin{array}{c}\text { Mean number of } \\
\text { enrolments }\end{array}$ \\
\hline Northeast & $172,360^{\mathrm{d}}$ \\
Northwest & $275,592^{\mathrm{c}}$ \\
Southsouth & $328,313^{\mathrm{b}}$ \\
Middlebelt & $394,490^{\mathrm{b}}$ \\
Southeast & $422,613^{\mathrm{ab}}$ \\
Southwest & $527,921^{\mathrm{a}}$
\end{tabular}

Note: values in the same column with the same superscript are not significantly

Results on Table 3 indicates that students' enrolment in the Southwest $(527,921)$ and the Southeast $(422,613)$ geopolitical zones were statistically similar. Compared to other geopolitical zones, enrolment was significantly 
lowest in the Northeast (172,360). There were no significant differences between students' enrolment in the Southeast, Middlebelt and Southsouth geopolitical zones, however, the number of students' enrolment in these three geopolitical zones were significantly higher than enrolment in the Northeast and Northwest (Table 3).

Generally, more students were enrolled in art subjects $(1,213,208.00)$ compared to science subjects $(908,081)$ between the years 2010 and 2015 . The significantly higher enrolment into arts than science subjects was found to reflect across most of the various years under investigation, except the year 2010 during which more students enrolled into science subjects $(143,068)$ than arts $(49,170)$ (Table 4).

Table 4. Results of students' enrolment into Science and Art subjects between 2010 and 2013

\begin{tabular}{ccc}
\hline Year & Science & Arts \\
\hline $\mathbf{2 0 1 0}$ & $143,068^{\mathrm{a}}$ & $49,170^{\mathrm{b}}$ \\
$\mathbf{2 0 1 1}$ & $119,905^{\mathrm{b}}$ & $224,931^{\mathrm{a}}$ \\
$\mathbf{2 0 1 2}$ & $191,259^{\mathrm{b}}$ & $234,111^{\mathrm{a}}$ \\
$\mathbf{2 0 1 3}$ & $167,736^{\mathrm{b}}$ & $245,136^{\mathrm{a}}$ \\
$\mathbf{2 0 1 4}$ & $132,092^{\mathrm{b}}$ & $221,984^{\mathrm{a}}$ \\
$\mathbf{2 0 1 5}$ & $154,021^{\mathrm{b}}$ & $237,876^{\mathrm{a}}$ \\
\hline
\end{tabular}

Note: values in the same row with different superscript are significantly

There was no significant difference between the number of male students enrolled in arts $(645,556)$ and science subjects $(595,126)$ in all the geopolitical zones between the investigated period (Table 5). On the contrary, significantly more female students were found to be enrolled into arts subjects $(567,652)$ than science subjects $(312,955)$. The results indicated that the number of male students $(595,126)$ enrolled in science subjects was significantly higher than the number of female genders $(312,955)$ enrolled in science subjects (Table 5). Though there were more male enrolments into arts subject than female, the difference was found not to be significant.

Table 5. Enrolment of male and female gender into Science and Art subjects in the study area

\begin{tabular}{ccc}
\hline Gender /Area of Specialization & Male & Female \\
\hline Science & $595,126^{\mathrm{a}}$ & $312,955^{\mathrm{b}}$ \\
Arts & $645,556^{\mathrm{a}}$ & $567,652^{\mathrm{a}}$ \\
\hline
\end{tabular}

Note: values in the same row with different superscript are significantly

Fig 1 shows the enrolment of students (male and female) from the six geopolitical zones of Nigeria into Arts and Science courses in higher institutions in Nigeria. Fig 1(a) reveals that in 2010, there was higher enrolment into Science than Art courses in the six geopolitical zones, while Figs 1(b) to (f) revealed otherwise, that is, there was generally higher enrolment in Arts than Science courses between 2011 and 2015 across geopolitical zones. Also, Fig 1 reveals that, in each year, while a higher number of females enrolled into Arts courses in the Southeast, Southwest, and Southsouth, a higher number of males enrolled into Sciences in these three (3) zones.
Also, in the two northern zones and the Middlebelt, male enrolments were higher for both Arts and Sciences. This means that in the six geopolitical zones of Nigeria, male enrolment was higher than female enrolment into Science courses.
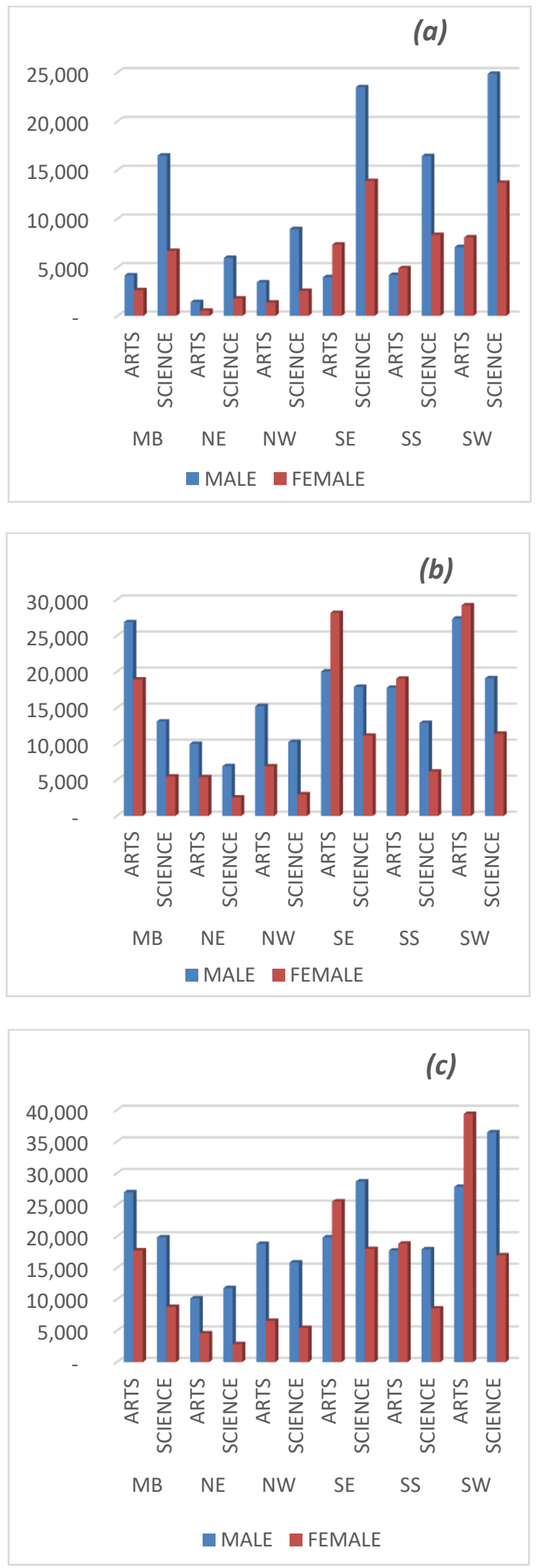


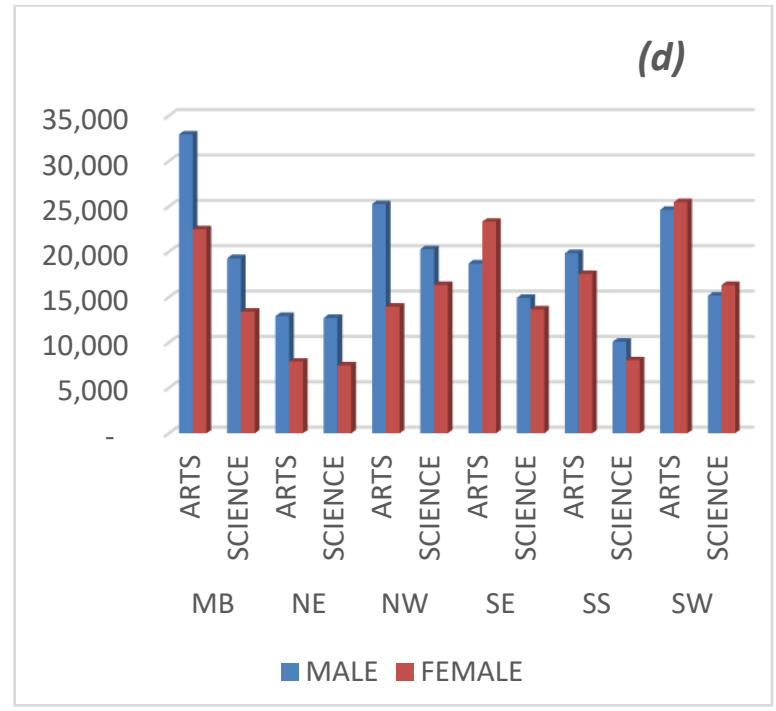

(e)

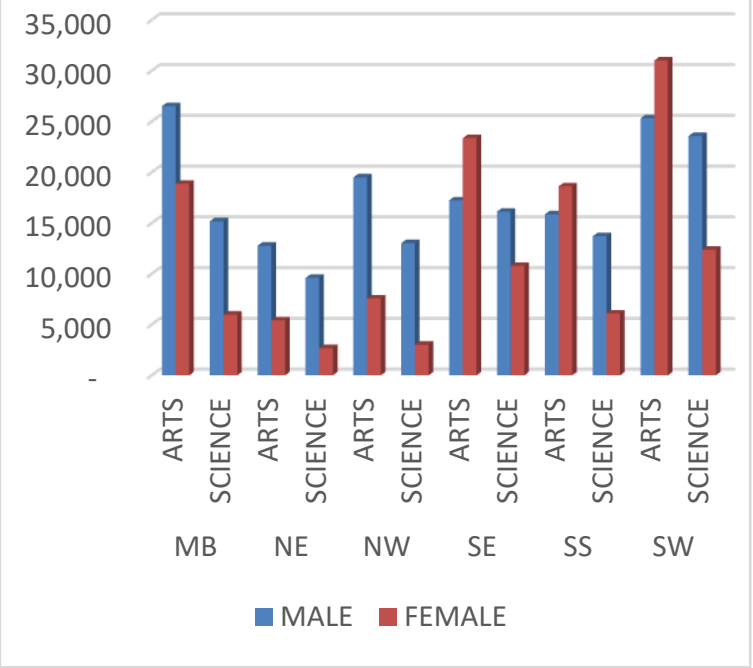

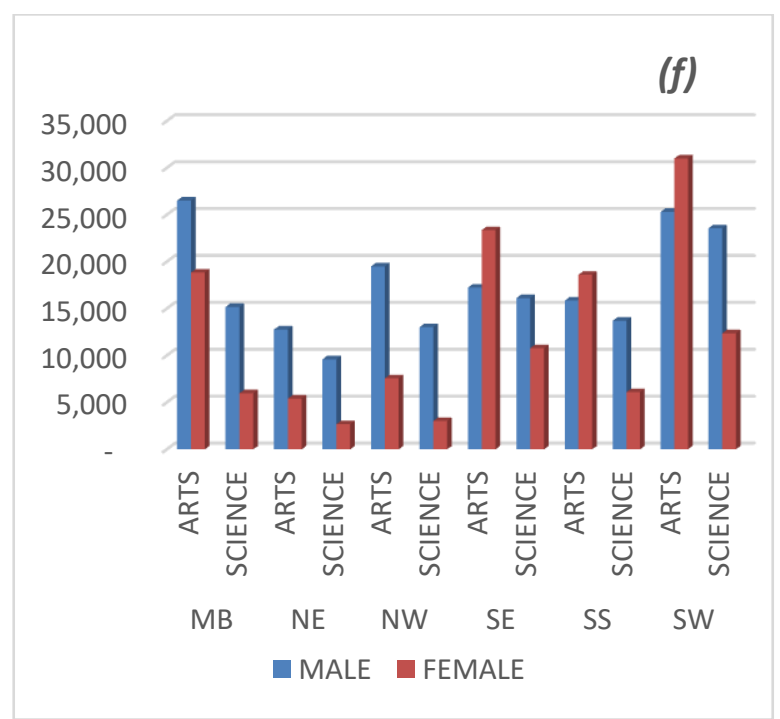

Fig.1. Enrolment of student from the six geopolitical zones of Nigeria into Art and Science courses in Higher Institutions in (a) 2010; (b) 2011 (c) 2012; (d) 2013; (e) 2014 and (f) 2015 (MB=Middlebelt,

$\mathrm{NE}=$ Northeast, $\mathrm{NW}=$ Northwest, $\mathrm{SE}=$ Southeast, $\mathrm{SS}=$ Southsouth, $\mathrm{SW}=$ Southwest)

Table 6 shows the percentage of male and female enrolment into Science courses in the six geopolitical zones in Nigeria. Depending on the geopolitical zone, percentage enrolment ranged from $60 \%$ to $75 \%$ for male students and from $25 \%$ to $40 \%$ for females (Table 6) while depending on the year, percentage enrolment varied from $52 \%$ to $81 \%$ for male students and from $19 \%$ to $52 \%$ for female students.

Table 6. Enrolment (\%) of male and female students into Science courses in the six geopolitical zones in Nigeria

\begin{tabular}{|c|c|c|c|c|c|c|c|c|c|c|c|c|}
\hline \multirow[t]{3}{*}{ YEAR } & \multicolumn{12}{|c|}{ Geopolitical zones } \\
\hline & \multicolumn{2}{|c|}{ MB } & \multicolumn{2}{|c|}{$\mathrm{NE}$} & \multicolumn{2}{|c|}{ NW } & \multicolumn{2}{|c|}{ SE } & \multicolumn{2}{|c|}{ SS } & \multicolumn{2}{|c|}{ SW } \\
\hline & M & $\mathrm{F}$ & M & $\mathrm{F}$ & $\mathrm{M}$ & $\mathrm{F}$ & M & $\mathrm{F}$ & $\mathrm{M}$ & $\mathrm{F}$ & M & $\mathrm{F}$ \\
\hline 2010 & 71 & 29 & 77 & 23 & 78 & 22 & 63 & 37 & 66 & 34 & 64 & 36 \\
\hline 2011 & 71 & 29 & 73 & 27 & 77 & 23 & 62 & 38 & 68 & 32 & 63 & 37 \\
\hline 2012 & 69 & 31 & 81 & 19 & 75 & 25 & 61 & 39 & 68 & 32 & 68 & 32 \\
\hline 2013 & 59 & 41 & 63 & 37 & 55 & 45 & 52 & 48 & 56 & 44 & 48 & 52 \\
\hline 2014 & 72 & 28 & 78 & 22 & 81 & 19 & 60 & 40 & 69 & 31 & 66 & 34 \\
\hline 2015 & 68 & 32 & 76 & 24 & 78 & 22 & 60 & 40 & 66 & 34 & 64 & 36 \\
\hline Avg & 68 & 32 & 75 & 25 & 74 & 26 & 60 & 40 & 66 & 34 & 62 & 38 \\
\hline
\end{tabular}

$\mathrm{MB}=$ Middlebelt, NE=Northeast, NW=Northwest, $\mathrm{SE}=$ Southeast, $\mathrm{SS}=$ Southsouth, $\mathrm{SW}=$ Southwest; $\mathrm{M}=$ male; $\mathrm{F}=$ Female.

Of particular interest is the analysis and comparison of female enrolment into Science subjects within the years under investigation (that is, 2010 to 2015) in the six geopolitical zones in Nigeria. The absolute numbers of female student enrolment in science subject in Nigerian Universities between 2010 and 2015 is shown in Fig 2. 


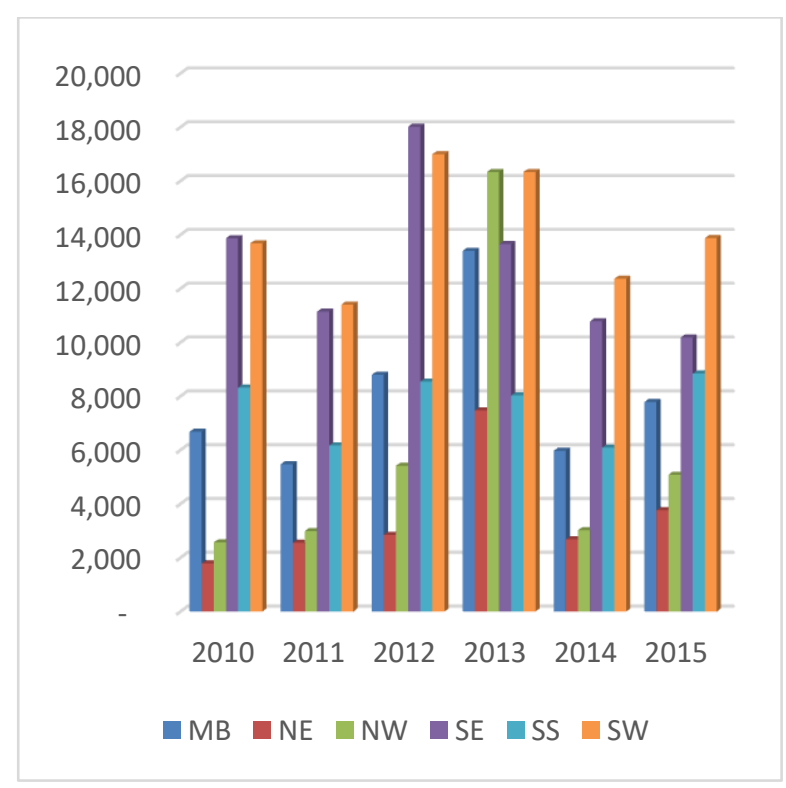

Fig.2. Enrolment of female students from the six geopolitical zones of Nigeria into Science courses in Higher Institutions in (a) 2010; (b) 2011; (c) 2012; (d) 2013; (e) 2014 and (f) 2015

Fig 2 shows the enrolment of females from the six geopolitical zones in Nigeria into Science courses from 2010 to 2015. From the illustration, it can be observed that, for reasons that cannot be immediately explained in this study, the Middlebelt, Northeast, and Northwest recorded high enrolment of females in Science subjects in 2013, which was not consistent with enrolments in the other years investigated in this study. It is clear that, in the other years, Northeast geopolitical zone recorded the lowest female enrolment, followed by Northwest, and Middlebelt. Female enrolments into Science courses in Southsouth was slightly higher than those in the Middlebelt in some years, while Female enrolments into Science courses in Southeast and Southwest were higher than those of the other geopolitical zones of the country (Fig 3).

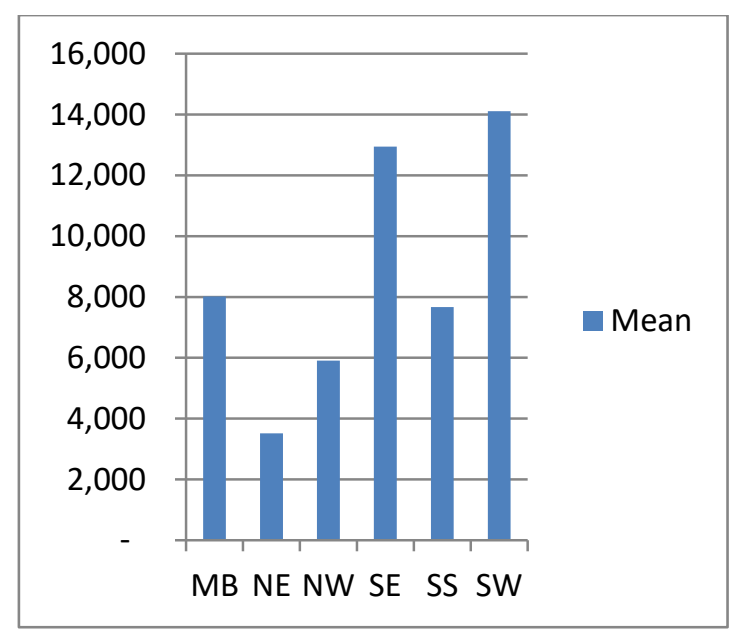

Fig.3. Mean of Female Enrolment into Science Courses in Nigeria by Geopolitical Zones

From Fig 4, it is obvious that during the period under investigation (2010 - 2015), $27 \%$ of the female enrolment into STEM courses in Nigeria was from Southwest, which was closely followed by the enrolment of female students from the Southeast $(25 \%)$. The results indicated that Southsouth and Middlebelt had an equal percentage of female enrolment (15\%) into STEM courses, $11 \%$ of female enrolment into STEM courses was accounted for by the Northwest, while the lowest percentage (7\%) of female enrolment into STEM courses was recorded in the Northeast geopolitical zone.

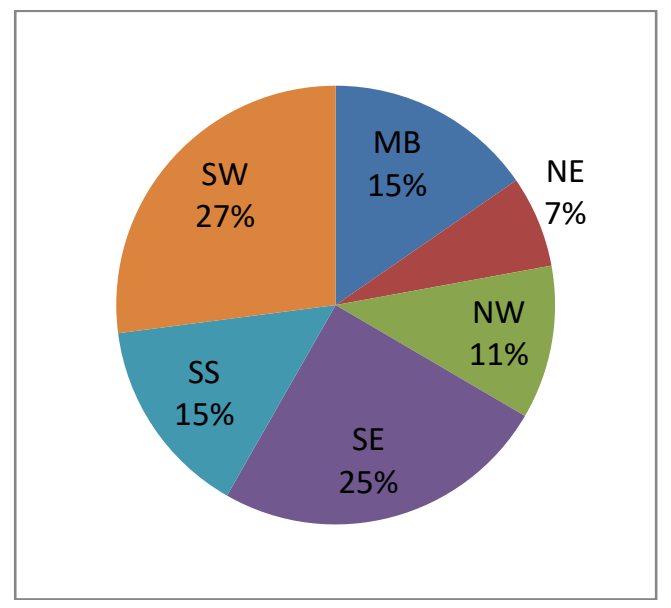

Fig.4. Percentage of Female enrolment into STEM Courses in Nigeria by Geopolitical Zones

\section{Gender Parity Index}

One of the major resolutions of the Millennium Declaration is that boys and girls should have equal access to all levels of education, by 2015 [8]. To measure the progress towards this declaration, the Gender Parity Index (GPI) is employed. UNESCO [9] defined the Gender Parity Index (GPI) as the ratio of female to male values of a given indicator. In this research, the specific indicator is enrolment into science courses in Nigerian University, by geopolitical zones. The Gender Parity Index was calculated by dividing the female value for the indicator (in this instance, enrolment), by the male value, that is:

$$
G P I=\frac{\text { female }}{\text { male }}
$$

From equation 1, if the resulting value is 1 , then it indicates that there is parity between the male and the female. A value that is less than 1 indicates a disparity in favor of males, while a value greater than 1 indicates a disparity in favor of the females. The GPI for the students'

Table 7. Gender Parity Index for Science Enrolment in different geopolitical zones of Nigeria

\begin{tabular}{ccccccc}
\hline Year & MB & NE & NW & SE & SS & SW \\
\hline 2010 & 0.41 & 0.30 & 0.29 & 0.59 & 0.51 & 0.55 \\
2011 & 0.42 & 0.37 & 0.29 & 0.62 & 0.48 & 0.60 \\
2012 & 0.44 & 0.24 & 0.34 & 0.63 & 0.48 & 0.47 \\
2013 & 0.69 & 0.59 & 0.81 & 0.91 & 0.80 & 1.08 \\
2014 & 0.39 & 0.28 & 0.23 & 0.67 & 0.44 & 0.52 \\
2015 & 0.46 & 0.32 & 0.28 & 0.65 & 0.51 & 0.57 \\
\hline $\begin{array}{l}\text { Mean } \\
\text { Index }\end{array}$ & 0.47 & 0.35 & 0.37 & 0.68 & 0.54 & 0.63 \\
\hline
\end{tabular}


enrolment, within the years under study (2010-2015), in the six geopolitical zones of Nigeria is shown in Table 7.

From Table 7 , it is clear that there is a disparity in female enrolment into STEM courses across the six geopolitical zones if Nigeria, with Southeast having the lowest disparity of 0.68 , and Northeast having the highest disparity of 0.35 (Table 7). The general trend of the results is that disparity increases as one moves from the southern part of Nigeria to the northern part of the country. This is evident from the generally lower GPI in the northern geopolitical zones (i.e. Northeast and Northwest) compared to those in the southern geopolitical zones (i.e. Southsouth, Southeast and Southwest). Of particular interest is male and female enrolments in 2013, when there was a disparity in favor of females in the Southwest geopolitical zone (GPI = 1.08) and GPI values of almost 1.0 in the other geopolitical zones (Table 8).

\section{Discussion}

From in the results of this study, it was first established that, within the period under study, that is, 2010 to 2015 , enrolment into Arts courses was generally higher than that into science courses across the six geopolitical zones in Nigeria. Secondly, with respect to enrolment into science courses, the results showed that male enrolment was higher than those of the female gender. Narrowing down the analysis to focus basically on female enrolment into science courses in the six geopolitical zones in Nigeria, the results revealed that the Southwest geopolitical zone recorded the highest percentage $(27 \%)$ of female enrolment into science courses, followed closely by the Southeast with $25 \%$ female enrolment. Both Southsouth and Middlebelt were next with each geopolitical accounting for $15 \%$ female student enrolment into science courses. This was followed by Northwest with $11 \%$ female enrolment while Northeast recorded the lowest female enrolment of $7 \%$.

Adeyemi and Akpotu [5] carried out a Gender analysis of student enrolment in Nigerian Universities, with data obtained from 1989 to 1997. Their findings showed that, as far back as 1989 to 1997 , there was a disparity of female to male. They also revealed that the disparity was wider in science-based disciplines on the one hand and in the northern zones on the other, which agrees with the results of the present study. Based on their findings, [5] made recommendations which included sustained enlightenment programs, fine-tuning of labor laws and accommodating females under the "educationally disadvantaged" admission policy currently enjoyed by some states in Nigeria.

Table 8. Undergraduate Enrolment (\%) in Science-based faculties by Region (Source: Aderemi, et al., 2013)

\begin{tabular}{ccccccccccc}
\hline \multirow{2}{*}{ YR } & \multicolumn{2}{c}{ MB } & \multicolumn{2}{c}{ NE } & \multicolumn{2}{c}{ NW } & \multicolumn{2}{c}{ SE } & \multicolumn{2}{c}{ SW } \\
\cline { 2 - 10 } & M & F & M & F & M & F & M & F & M & F \\
\hline 1997 & 78 & 22 & 76 & 24 & 85 & 15 & & & 33 & 67 \\
1998 & 73 & 27 & 76 & 24 & 78 & 22 & 62 & 38 & 40 & 60 \\
1999 & 79 & 21 & 73 & 27 & 77 & 23 & 64 & 36 & 25 & 75 \\
2000 & 69 & 31 & 67 & 33 & 71 & 29 & 60 & 40 & 80 & 20 \\
2001 & 76 & 24 & 67 & 33 & 70 & 30 & 34 & 66 & 23 & 77 \\
2002 & 66 & 34 & 31 & 69 & 79 & 21 & 62 & 38 & 29 & 71 \\
2003 & 76 & 24 & 67 & 33 & 79 & 21 & 60 & 40 & 24 & 76 \\
2004 & - & - & 74 & 26 & 71 & 29 & 60 & 40 & 23 & 77 \\
2005 & 73 & 27 & 88 & 12 & 60 & 40 & 59 & 41 & 38 & 62 \\
2006 & 73 & 27 & 66 & 34 & 69 & 31 & - & - & 33 & 67 \\
Avg & 74 & 26 & 69 & 31 & 74 & 26 & 58 & 42 & 35 & 65 \\
\hline
\end{tabular}

Table 9. Comparison of average percentage of Male and Female Enrolment into Science Courses

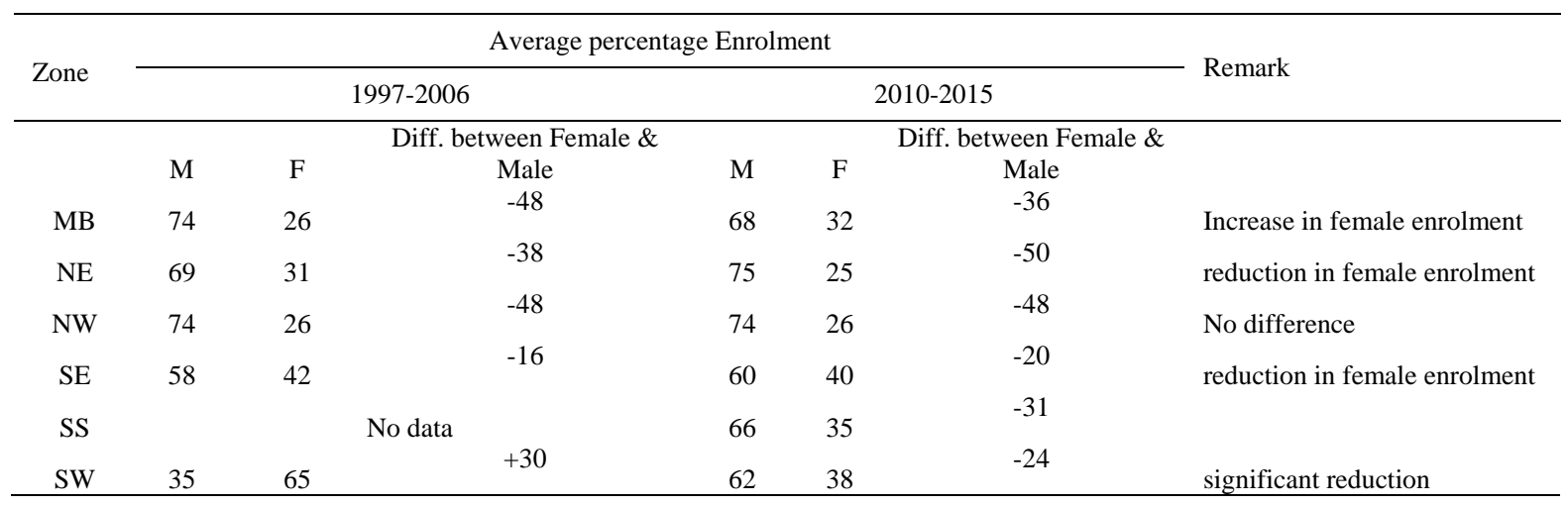


Reference [6] carried out an analysis of enrolment into science courses from 1997 to 2006 and revealed a similar trend in the percentage of male and female enrolment in this study. Their results are shown in Table 7. However, contrary to the results of this present study, Reference [6] showed that the percentage of female enrolment was consistently higher than that of male enrolment in the Southwest geopolitical zone of Nigeria between 1997 and 2006. They inferred that there was more awareness for female students to study science courses over the period under study.

The average percentage of male and female enrolment into science course in all the geopolitical zones between the periods covered by [6] (i.e. 1997 to 2006) was computed and compared with that of the period covered in this study (i.e. 2010 to 2015). (Table 8).

The average percentage enrolment of male and female students in all the geopolitical zones and the was computed and compared

The results showed that in the Middlebelt geopolitical zone the percentage difference in male to female enrolment reduced from $48 \%$ between 1997 and 2006 to $36 \%$ between 2010 and 2015 . This is an indication that there was an increase in female enrolment in the Middlebelt between 2010 and 2015 compared with 1997 and 2006 enrolment figure. While this increase in female enrolment between 2010 and 2015 is a welcome development, it is still evident that female enrolment into science courses in the Middlebelt is less than half that of their male counterpart. Contrary to the increase in female enrolment into science courses recorded in the Middlebelt, there was a decrease in female enrolment in the Northeast, Southeast, and Southwest between 2010 and 2015 compared with 1997 and 2006 enrolment figure (Table 6). For example, in the Northeast, the difference in the female to male enrolment increased from $-37 \%$ (between 1997-2006) to $-50 \%$ (between 2010 to 2015). The Southeast geopolitical zone had a similar trend, with the difference in the female to male enrolment increasing from $-16 \%$ to $-20 \%$ during the periods $1997-2006$ and 2010 to 2015, respectively. In the Northwest geopolitical zone, there was no difference in the female to male enrolment between 1997-2006 and 2010 to 2015. Aderemi et al. [6] did not present data for Southsouth between 1997 and 2006, thus no comparison could be made for this geopolitical zone. When the results of the present study for Southwest zone was compared with that of [6], it became evident that the Southwest geopolitical zone recorded the highest drop in female enrolment into Science Courses, with the difference in female to male enrolment decreasing from $30 \%$ between 1997-2006 to $-27 \%$ between 2010 to 2015 .

The above comparative analysis implies that there is a decline in the enrolment of females into Science courses in the University in five out of the six geopolitical zones of Nigeria. While there has been some propaganda to encourage the female folks to study science, it is clear that the efforts made are not yielding the required results, as shown by the comparison.
Bridging the science gap between male and female in Nigerian educational systems needs to be taken beyond passive policies to active processes which should involve proper investigation, actions plans, well-monitored results, and active feedback mechanism. Reference[10] pointed out several actions already in place by some private sectors within the country, to support the inefficient attempts by the Government to bridge the cap. Some of the private sector initiatives are; Government-funded projects like the Junior Engineers, Technologists, and Scientist (JETS) initiatives, Science, Maths and Technology (SMT) clinics for girls in specific institutions, career counseling, Information campaigns, Scientific awards and prizes, Science fairs. Some of these, however, still have very little coverage across the nation.

The following recommendations are hereby made

1. Parental perception of girls' abilities: Reference [11] observed that some parents had higher perceptions of science abilities and higher expectations of success in Science education for their male children than for the female children. Sensitization and propaganda can be carried out on media platforms to alter this perception. Parents with the right perception will encourage their girls right from tender ages to embrace science.

2. The Federal Character policy for admission was instituted to cater for disadvantaged states in Nigeria. Similar policy can be created to create more opportunities for females to be admitted for science courses.

3. Role Models: Although the country can boast of a relatively moderate number of women who are top-flyers in Science oriented careers, many of them are not known. The Education sector can seek out these women and involve them in career counseling and drives to mentor young girls.

4. Scholarships, grants, and other incentives can be introduced specifically for the girl child. The International Community offers lots of scholarships with focus on the girls. From Europe, we have the Erasmus Mundus Scholarships initiated by the European Commission, VLIR-UOS Training and Masters Scholarships by Belgium, the DAAD by Germany, and a host of others. However, most of them are for Masters' degree programs outside the country. Organizations within the country can design such scholarships to encourage girls to study science within the country.

\section{CONCLUSION}

From the comparative analysis carried out in this research, it is clear that there is still a relatively high disparity in the enrolment of females into science courses in Nigerian Universities, when compared with that of their male counterparts. More alarming is the finding that, when compared with previous years' analysis, there is a decline 
in female enrolment into science courses in most of the geopolitical zones in Nigeria. This calls for more intensive measures to correct this disparity. Gender inequality is a problem that is attracting lots of attention worldwide. Bridging this gap in the field of science education will go a long way in enhancing gender equality.

\section{REFERENCES}

[1] Aderemi, H.O., Hassan, O.M., Siyanbola, W.O., Taiwo, K (2013) Trends in enrolment, graduation and staffing of science and technology education in Nigeria tertiary institutions: A gender participation perspective. In Academic Journals, 8(21): 2011-2020, DOI:10.5897/ERR08.084, ISSN 1990-3839

[2] Adeyemi, K. and Akpotu, N. (2004). Gender analysis of student enrolment in Nigerian universities. Higher Education, Kluwer Academic Publishers. Printed in the Netherlands, 48: 361-378,

[3] Akinsowon, O. A. and Osisanwo, F. Y. (2014). Enhancing Interest in Sciences, Technology and Mathematics (STEM) for the Nigerian Female Folk. International Journal of Information Science, 4(1): 8-12 DOI: 10.5923/j.ijis.20140401.02

[4] Akpoyovwaire, S. M. (2014). Gender Participation in University Education in Nigeria: Closing the Gap. International Letters of Social and Humanistic Sciences Online: 2014-07-05 ISSN: 2300-2697, 34: 53-62. doi:10.18052/www.scipress.com/ILSHS.34.53

[5] Amelink, C. (2009). Gender Differences in Science Performance, SWE-AWE CASEE Overviews, Assessing Women in Engineering, SWE-AWE-CASEE ARP Resources, http://www.AWEonline.org. Assessed on 02/06/2018

[6] British Council Report (2014). Girls' Education in Nigeria: Issues, Influencers, and Actions. The British Council.

[7] Mills, M, van de Bunt, G. G., and de Brujin, J (2006), Comparative Research. Persistent Problems and Promising Solutions. International Sociology, 21(5): 619631, DOI: 10.1177/0268580906067833

[8] National Bureau of Statistics (2016), Annual Abstract of Statistics, 1. (217)

[9] Sawyer, S. F. (2009), Analysis of Variance: The Fundamental Concepts, in The Journal of Manual \& Manipulative Therapy $\mathrm{n}$ volume 17 number 2 [27-38], http://jmmtonline.com/documents/v17n2/sawyer.pdf. Assessed on 22/11/2018

[10] Udeani, U. (2012), Increasing Female Participation in Science and Technology Careers: Problems and suggested Interventions from Nigeria, Developing Country Studies, ISSN 2224-607X (Paper) ISSN 2225-0565 (Online) Vol 2 , No.5.

http://www.cssia.org/pdf/20000193-IncreasingFemale Participationin Scienceand TechnologyCareers.pdf. Assessed on 31/7/2018

[11] UNESCO (2010), Gender Parity in Primary and Secondary Education, UNESCO Institute of Statistics, Fact Sheets No. http://uis.unesco.org/sites/default/files/documents/fs4-gen der-parity-in-primary-and-secondary-education-en.pdf. Assessed on 31/07/2018

[12] UNESCO (2018), Gender Parity Index, Sustainable Development Goals, UNESCO Institute of Statistics, http://uis.unesco.org/en/glossary-term/gender-parity-index -gpi. Assessed on 23/07/2018.

\section{Author's Profile}

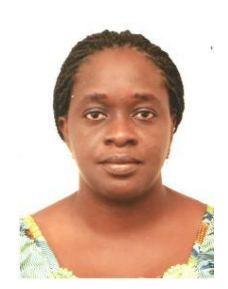

Onyekwelu, Bukola Abimbola

Place \& Date of Birth: Ado-Ekiti, Nigeria, 05 Dec. 1970

\section{Educational Background:}

- Ph.D. in Computer Science, Federal University of Technology, Akure, Ondo State., Nigeria - 2015

- M.Tech in Computer Science, Federal University of Technology, Akure, Ondo State, Nigeria-2009

- Post-Graduate Diploma in Computer Science, Federal University of Technology, Akure, Ondo State, Nigeria $-2004$

- B.Tech in Computer Science, Federal University of Technology, Akure, Ondo State, Nigeria-1991

Research/Area of Interest: CyberSecurity, Intrusion Detection, Science, Technology, Engineering and Mathematics (STEM) Initiatives.

\section{Working Experience}

- Lecturer I, Department of Mathematics and Computer Science, Faculty of Basic and Applied Sciences, Elizade University, Ilara-Mokin, Ondo State. January 2018 to date

- Lecturer I, Department of Computer Science, College of Natural Sciences, Joseph Ayo Babalola University, Ikeji-Arakeji, Osun State. October 2016 to December 2017

- Lecturer II, Department of Computer Science, College of Natural Sciences, Joseph Ayo Babalola University, Ikeji-Arakeji, Osun State. October 2013 to September 2016

- Assistant Lecturer, Department of Computer Science, College of Natural Sciences, Joseph Ayo Babalola University, Ikeji-Arakeji, Osun State. March 2010 to September 2013

- Lecturer (Part-time), Department of Computer Studies, Federal Polytechnic, Ado-Ekiti, Ekiti State. May to August 2009

Membership of Professional Bodies

- Member, Society of Digital Information and Wireless Communications (SDIWC)

- Member, Computer Professionals of Nigeria (CPN)

- Member, Nigerian Computer Society (NCS)

- Member, Nigerian Women In Information Technology (NIWIIT)

Member, Organization for Women in Science for the Developing World (OWSD) 
How to cite this paper: Bukola A. Onyekwelu, "Comparative Empirical Analysis of Female University Enrolment in STEM Courses in the Geopolitical Zones in Nigeria", International Journal of Modern Education and Computer Science(IJMECS), Vol.11, No.1, pp. 24-32, 2019.DOI: 10.5815/ijmecs.2019.01.03 